\title{
Simulación de escenarios futuros de cambios de usos del suelo usando Redes Neuronales Artificiales. Aplicación en la ciudad de Curuzú Cuatiá, Corrientes, Argentina
}

\section{Simulation of future scenarios of land use changes using Artificial Neural Networks. Application in Curuzú Cuatiá city, Corrientes, Argentina}

Laura Fabiana Gómez

Agrimensora. Especialista en Tecnología de la Información Geográfica. Becaria Doctoral del Consejo Nacional de Investigaciones Cientificas y Técnicas (CONICET). Departamento de Agrimensura. Facultad de Ciencias Exactas, Naturales y Agrimensura (FaCENA). Universidad Nacional del Nordeste. Consejo Nacional de Investigaciones Cientificas y Técnicas (UNNE/CONICET). 9 de Julio 1449, (3400) Corrientes, Argentina, laura.f.gomez@gmail.com, ORCID https://orcid.org/0000-0003-2114-3302

Recibido: 22 de agosto 2019 || Aprobado: 1 de junio 2020

Resumen

Las simulaciones de escenarios de usos del suelo futuros permiten obtener resultados que puedan convertirse en información valiosa para planificadores del territorio en tanto disminuyen el grado de incertidumbre. El objetivo del trabajo es la simulación de un escenario de usos de suelo de trayectoria lineal para el año 2030 de la ciudad de Curuzú Cuatiá, Corrientes. Factores topográficos, distancias y áreas inundables definidas por normativa vigente fueron escogidas como variables explicativas de los cambios, se utilizó un modelo basado en redes neuronales artificiales disponible en el Modelador de Cambios del Terreno (LCM) del software Idrisi Selva, junto con dos mapas de usos del suelo de cinco categorías elaborados para dos momentos del pasado. Los resultados obtenidos muestran los mapas de potenciales de transición hacia el Área Urbana Consolidada con precisiones mayores al 72\%; escenarios simulados al año 2030 y se determinaron las superficies de cada categoría, encontrando aumento de la clase Urbana Consolidada. Se completó el estudio con la validación del modelo por clase, mediante la fiabilidad global y el índice Kappa.

Palabras clave: Simulación; Escenarios Futuros; Cambios de usos del suelo; Redes Neuronales Artificiales

Abstract

Simulations of future land use scenarios allow obtaining results that can become valuable information for land planners while decreasing the degree of uncertainty. The aim of this contribution is to simulate a linear path land use scenario with a linear trajectory for the year 2030 in the city of Curuzú Cuatiá, Corrientes. Topographic factors, distances and flood areas defined by current regulations were chosen as explanatory variables of the changes, a model based on artificial neural networks, included in the Land Change Modeler -LCM- in the Idrisi Selva software was used, in addition to two maps of land uses of five categories elaborated for two moments of the past. The results obtained show the maps of transition potentials

Cita sugerida: Gómez, L.F. (2020). Simulación de escenarios futuros de cambios de usos del suelo usando Redes Neuronales Artificiales. Aplicación en la ciudad de Curuzú Cuatiá, Corrientes, Argentina. Estudios Socioterritoriales. Revista de Geografía, (28), 054. DOI: https://doi.org/10.37838/unicen/est.28-054 
towards the Consolidated Urban Area with accuracies greater than $72 \%$; simulated scenarios for the year 2030 (hard and soft prediction), and the surfaces of each class at each moment were determined, finding the increase only of the Urban Consolidated class in all of them. The study was completed with the validation of the model by class, using the global reliability and the Kappa index.

Key words: Simulation; Future Scenarios; Land use change; Artificial Neural Network

\section{INTRODUCCIÓN}

El crecimiento de la población, la necesidad de acceder a una vivienda propia y la presión ejercida por el mercado inmobiliario, hace imprescindible ordenar y planificar los espacios destinados a la expansión del suelo urbano. Tomando en cuenta que en muchos casos la normativa, los planes de ordenamiento y la política de regularización dominial, entre otras cuestiones, surgen a posteriori del avance espontáneo del área urbana, la modelización del crecimiento urbano y de los cambios de usos del suelo para simular alternativas de escenarios futuros, se convierten en una potente herramienta para el monitoreo del territorio por parte de planificadores y tomadores de decisiones.

Un modelo es una representación simplificada de un objeto real o fenómeno complejo de la realidad que pretende facilitar su comprensión y el estudio de su comportamiento; refleja sus propiedades más importantes en función de lo que se desee estudiar sobre él, dejando de lado los datos accesorios, para ser reproducido o imitado. En particular, un modelo espacial es un objeto de investigación con dos componentes: localización y atributo (Wegener, 2000).

En relación a la gestión del territorio, los modelos son centrales debido a la imposibilidad de manipular objetos, costos, tiempo y escalas en espacios urbanos (La Macchia, 2014).

La elaboración de modelos de prospección que tengan en cuenta los procesos y tendencias actuales se convierten en una herramienta para la representación de escenarios futuros que plantean discusiones acerca de la sostenibilidad de los crecimientos, los impactos de las políticas sectoriales, etc. (Santos Preciado, Azcárate Luxán, Cocero Matesanz, García Lázaro y Muguruza Cañas, 2012, p. 85)

Respecto de los escenarios, se los considera una descripción de una situación hipotética de futuro con el fin de conocer o aproximarse lo más posible a la realidad futura con base en una integración de diferentes puntos de vista, modelos y datos, que posibilitan esclarecer y respaldar la planificación y las políticas de usos del suelo (realizadas en el presente) ante cierto futuro posible (Veldkamp y Lambin, 2001). No se los considera como una verdad absoluta que refleja lo que indefectiblemente sucederá en el futuro, sino una de las posibilidades de lo que ocurrirá (entre otras) bajo determinadas condiciones (enfoque exploratorio en términos de Aguilera Benavente, Plata Rocha, Bosque Sendra y Gomez Delgado, 2009).

En este contexto, los Sistemas de Información Geográfica adquieren especial protagonismo al ser un instrumento capaz de crear observaciones, confrontarlas con casos reales y simular posibles configuraciones espaciales proyectadas a futuro, que permitan acceder a otra realidad y operar sobre ella a fin de extraer resultados aplicables al mundo empírico (Buzai y Baxendale, 2011).

En relación al crecimiento del área urbana de una ciudad y su dirección, varios auto- 
res expresan que existen diversos factores que inciden sobre el mismo y lo determinan, como ser la topografía, los equipamientos, el valor del suelo (Cifuentes Ruiz, 2009), los nuevos estilos de vida en ambientes suburbanos, la mejora en las redes de transporte y movilidad de los ciudadanos (Plata Rocha, Bosque Sendra y Gómez Delgado, 2011), factores derivados de aspectos socioeconómicos, legales y administrativos y derivados de la proximidad (Baluja Arestiño, Plata Rocha, Gómez Delgado y Bosque Sendra, 2010). Aunque de la relación entre el crecimiento urbano y tal diversidad de factores presentes en el territorio no es posible deducir una consecuencia directa, el entendimiento de la misma se convierte en un elemento más para la comprensión de las problemáticas actuales y disminución de la incertidumbre de las problemáticas y demandas futuras.

De acuerdo con lo expuesto, este trabajo tiene como objetivo la generación de un escenario de usos de suelo de trayectoria lineal para el año 2030 en la ciudad de Curuzú Cuatiá, provincia de Corrientes, Argentina. Este escenario surge bajo el supuesto de que ciertos factores que influyen en los cambios de los usos del suelo actuarán de la misma manera a como lo hicieron en el pasado. Por lo tanto, nos proponemos responder las siguientes preguntas: ¿cuáles son las variables consideradas importantes para la expansión urbana de la ciudad?, ¿dónde se localizan las áreas de mayor probabilidad de transformación hacia el Área Urbana Consolidada (AUC)?, ¿cuál es el grado de validez que posee el modelo utilizado para simular un escenario de trayectoria lineal?

\section{Área de Estudio}

La ciudad de Curuzú Cuatiá se localiza en la región centro-sur ${ }^{1}$ de la provincia de Corrientes (República Argentina) (2947'30"LS y 5803'16"LW) a 328 kilómetros al sudoeste de la capital. Es la cabecera del departamento y del municipio de nombre homónimo que además incluye las localidades de Cazadores Correntinos y Perugorría (Mapa 1). La población de Curuzú Cuatiá alcanzó en el año 2010 los 34.470 habitantes (INDEC, 2010), posicionándose en cuarto lugar en la provincia ${ }^{2}$ y se identifica como una ciudad intermedia del sistema urbano correntino al configurarse como un nodo organizador de la región a la que pertenece (Gómez y Ramírez, 2019).

De acuerdo con estudios previos (Gómez y Ramírez, 2019) se ha advertido el ritmo y la tendencia de la expansión que esta ciudad ha experimentado en los últimos treinta años ${ }^{3}$. Específicamente utilizando un polinomio de tercer grado ${ }^{4}$, es posible visualizar el comportamiento general de los cambios de usos de suelo hacia el Área Urbana Consolidada (AUC) ${ }^{5}$

1 Incluye los departamento de Curuzú Cuatiá, Mercedes, Monte Caseros, Paso de los Libres y Sauce (Ley Provincial N 5.960 art. 39).

2 Es un asentamiento urbano que forma parte de un conjunto de 37 ciudades de más de 2.000 habitantes en el territorio provincial.

3 El área de estudio considerada se delimitó usando una máscara basada en el polígono urbano provisto por el IGN (www.ign.gob.ar, consulta agosto de 2015), y con el fin de evitar que en el segundo período analizado la mancha urbana exceda la extensión delimitada por el IGN, se amplió su extensión en un kilómetro utilizando para ello un buffer de polígono (Gómez y Ramírez, 2019).

4 "La superficie se crea codificando áreas de cambio con 1 y áreas de no cambio con 0 y tratándolas como si fueran valores cuantitativos" (Eastman, 2012).

5 Definida según la Ley Orgánica de las municipalidades como todo aquel fraccionamiento en manzanas o unidades equivalentes, determinadas total o parcialmente por calles, como asimismo aquellas parcelas que no estando fraccionadas estén rodeadas parcial o totalmente por fraccionamiento en manzanas o unidades equivalentes, destinadas a asentamientos humanos intensivos, en los que se desarrollan usos vinculados con la residencia, las actividades terciarias y de producción compatibles (Ley Provincial $N^{\circ} 4.752 / 93$ ). 
(Mapa 2). Los valores fueron normalizados entre 0 y 1 , donde valores que se acercan al 1 indican mayor tendencia al cambio.

En términos generales, la expansión se observa de manera más acentuada en las proximidades de la Ruta Nacional $N^{\circ} 119$, en el sector del acceso a la ciudad. Asimismo, se puede observar que la distribución espacial de los cambios adquiere forma elíptica, ensanchándose en sentido este-oeste.

Mapa 1. Localización de la provincia de Corrientes en Argentina (izquierda). Localización del departamento Curuzú Cuatiá en la provincia de Corrientes y su ciudad cabecera (derecha)

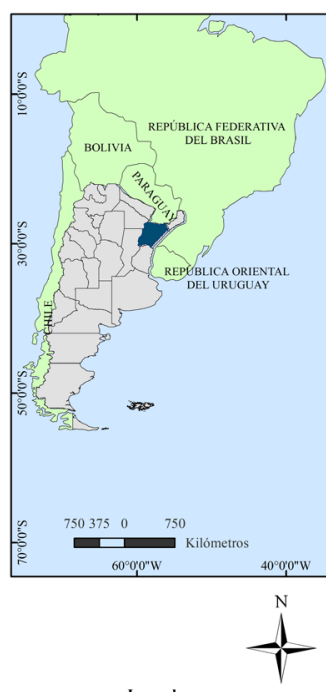

Leyenda Provincia de Corrientes Región Centro-Sur Departamento Curuzí Cuatíá

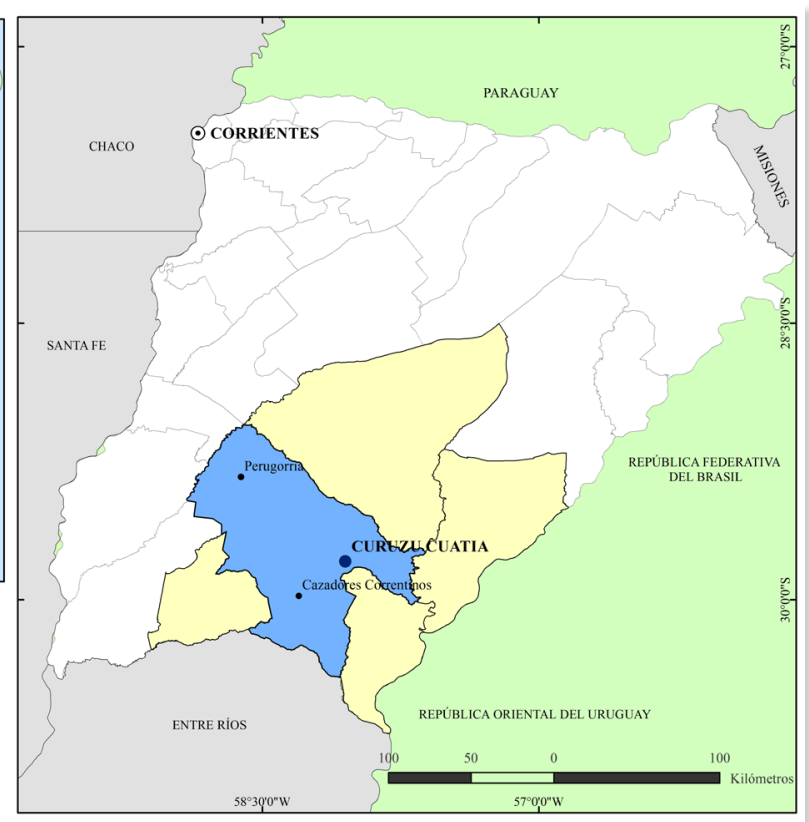

Fuente: elaboración personal con base en archivos vectoriales del Instituto Geográfico Nacional (IGN)

Mapa 2. Tendencia de los cambios de usos de suelo entre 1990 y 2010

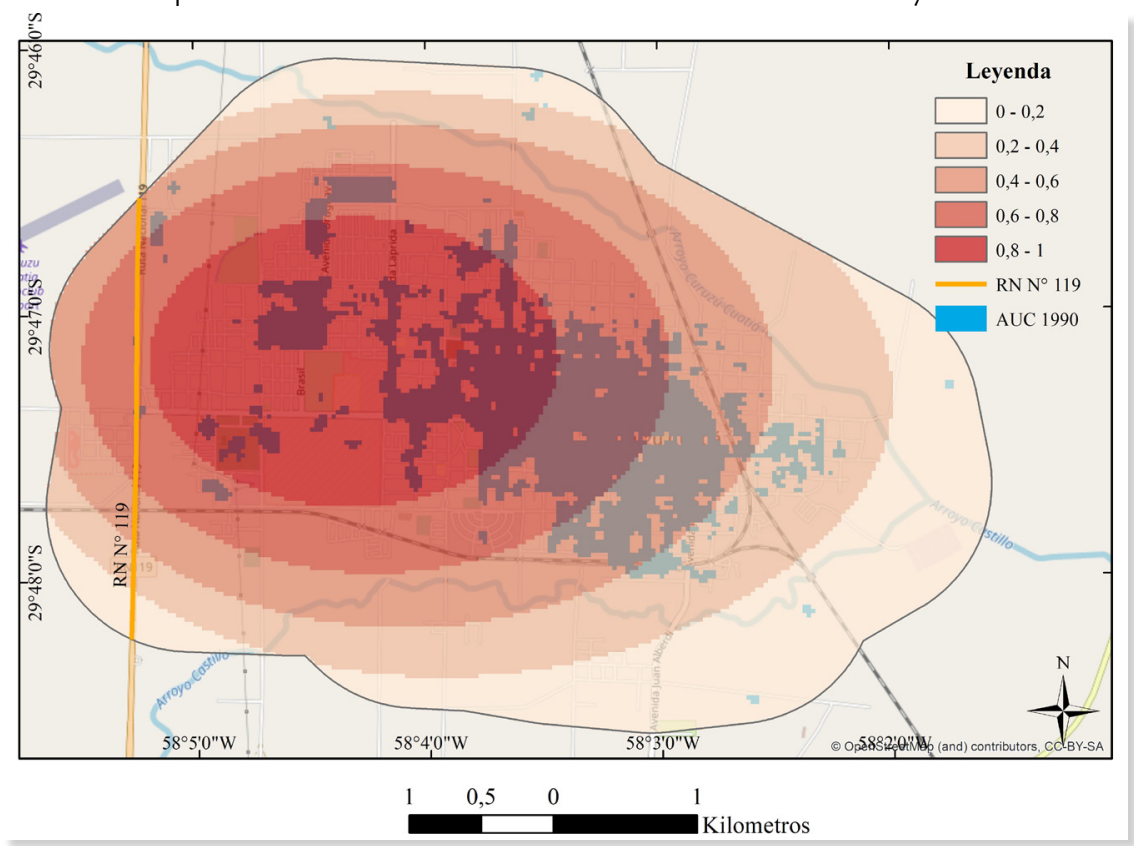

Fuente: elaboración personal 


\section{MATERIALES Y MÉTODOS}

DATOS

Para la realización de los escenarios futuros fue necesario el cruce de dos mapas de usos del suelo de diferentes momentos, pues el modelo utilizado depende del comportamiento de la variable a modelar en el pasado. Para este trabajo se utilizaron mapas de usos del suelo para los años 1990 y 2010 en formato ráster, con leyendas idénticas, generados a partir de una clasificación supervisada con base en imágenes Landsat 5 - TM y Landsat 8 - OLI (según disponibilidad en función para los años considerados), cuyas resoluciones espaciales son de 30 m (Gómez y Ramírez, 2019) (Mapas 3a y 3b) .

Mapas 3a y 3b. Mapas de usos de suelo de la ciudad de Curuzú Cuatiá. Años 1990 y 2010

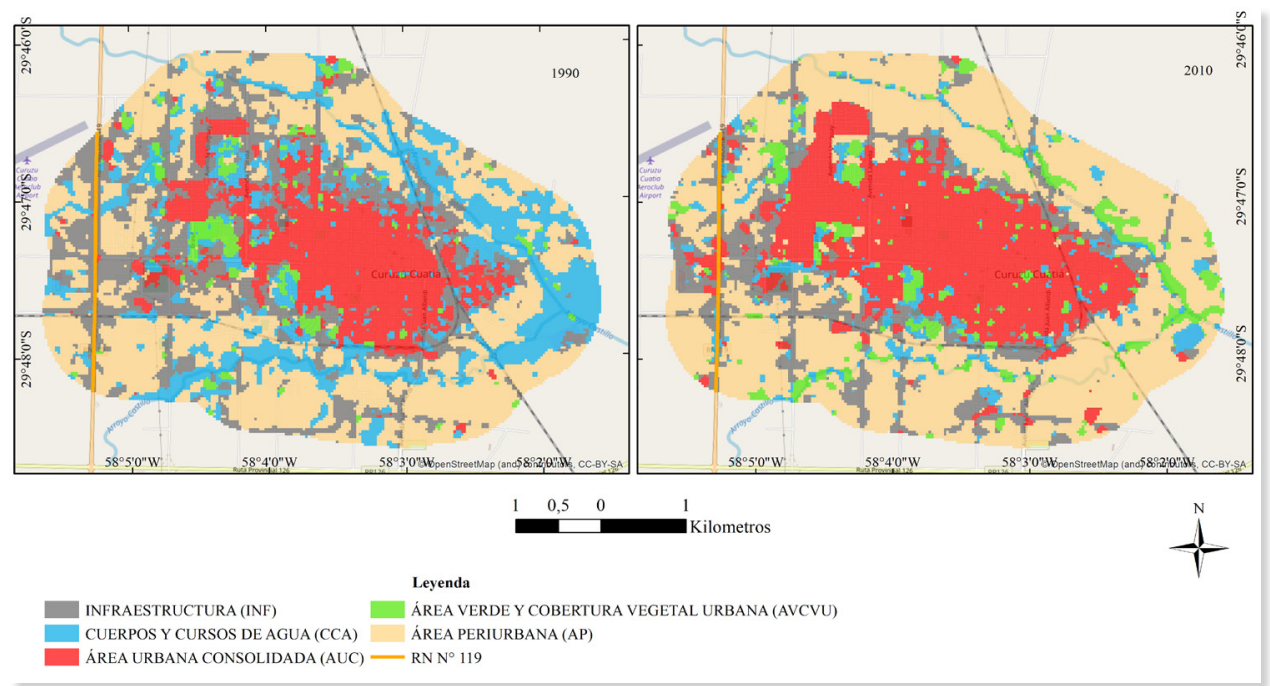

Fuente: elaboración personal

El modelo también requiere como inputs un conjunto de factores explicativos de los cuales dependerá en menor o mayor medida la validez del escenario simulado. Estos factores dependerán del área de estudio y de la disponibilidad, accesibilidad y actualización de datos, y finalmente condicionarán la localización de los posibles usos de suelo simulados. En este trabajo los factores explicativos (o variables) considerados se escogieron de entre aquellas que se consideraron relevantes para el cambio de uso de suelo hacia el AUC. Se debe tener en cuenta que no todos los procesos que generan cambios pueden ser modelados y que los mismos dependerán de la escala espacial (Alcamo, Kok, Busch y Priess, 2008). Además, las variables seleccionadas pueden ser estáticas o dinámicas (cambian con el tiempo), de tipo biofísica, demográficas, socioeconómica o de proximidad a los servicios, infraestructuras, entre otros. A continuación se detallan las variables exploradas:

Distancia a la zona cívico, administrativa y comercial de la ciudad (Estática): Distancia euclídea a partir del polígono determinado por ordenanza municipal, que establece la zonificación de la ciudad de Curuzú Cuatiá, medida en metros. Fuente: elaboración personal con base en Ordenanza Municipal N².410/06.

6 Estos mapas son el resultado de una investigación anterior publicada en la revista Estudios Marítimos y Sociales (Gómez y Ramírez, 2019). 
MDE (Estática): Modelos Digitales de Elevación, medidos en metros. Fuente: Servicio Geológico de los Estados Unidos-USGS (https://earthexplorer.usgs.gov/, fecha de descarga 19 de agosto de 2015).

Distancia al AUC (Dinámica): Distancia euclídea a partir de los píxeles clasificados como AUC en el mapa de usos del suelo del año 1990, medida en metros. Fuente: elaboración personal.

Distancia a los cursos de agua (Estática): Distancia euclídea a partir del polígono generado al realizar un buffer de 15 metros a los cursos de agua existentes en la ciudad, medida en metros. Fuente: elaboración personal con base en la capa vectorial de cursos de agua disponible en www.IGN.gob.ar (fecha de descarga 24 de abril de 2018).

Área inundable y no inundable (Estática): Variable cualitativa representada por los píxeles que se obtienen mediante la combinación de la normativa vigente en la Ciudad de Curuzú Cuatiá y el modelo digital de elevación. Fuente: elaboración personal con base en la Ordenanza Municipal N³59/86 y el MDE provisto por el USGS (https://earthexplorer.usgs.gov/, fecha de descarga 19 de agosto de 2015).

Pendiente (Estática): Tasa máxima de cambio del valor de una celda en relación a sus ocho vecinas, medida en porcentaje. Fuente: elaboración personal.

Distancia a equipamientos educativos de nivel primario y secundario (Estática): Distancia euclídea a partir de la localización de los establecimientos educativos de nivel primario y secundario, medida en metros. Fuente: elaboración personal con base en la capa vectorial de equipamientos educativos disponible en http://mapa. educacion.gob.ar/mapa-interactivo (fecha de descarga 26 de febrero de 2019).

$\sim$ Distancia a rutas nacionales y provinciales (Estática): Distancia euclídea a partir las líneas que representan a las rutas nacionales y provinciales que atraviesan el polígono considerado como área de estudio en cada ciudad, medida en metros. Fuente: elaboración personal con base en la capa vectorial de red vial disponible en www.IGN.gob. ar (fecha de descarga 21 de julio de 2015).

Distancia a áreas verdes ${ }^{7}$ (Estática): Distancia euclídea considerada a partir de aquellos píxeles clasificados como Área Verde y Cobertura Vegetal Urbana (AVCVU) ${ }^{8}$ en el año 1990 cuya superficie fue de al menos 14.400 m2, medida en metros (Fuente: elaboración personal).

La selección final de las variables usadas para correr el modelo se presentan en el apartado de resultados.

Al momento de validar el modelo calibrado, se utilizó un tercer mapa de coberturas y usos de suelo de otro momento, al cual se lo considera como 'verdad de terreno'9 (año

7 Este valor de distancia surge a partir de los píxeles clasificados como AVCVU, en ocasión de la generación de los mapas de usos del suelo, y que poseen contigüidad espacial definiendo superficies de al menos una manzana o una hectárea.

8 Espacio con predominio de parques, plazas, jardines, paseos, parterres (espacios verdes lineales y jardines centrales en vías públicas) plantíos, vegetación arbórea. Elaboración personal (Gómez y Ramírez, 2019).

9 Este mapa se validó haciendo uso de imágenes de mayor resolución espacial provenientes de Google Earth. El porcentaje de fiabilidad global de la clasificación realizada fue del 78,83\% (obtenido en base a un análisis realizado sobre una muestra seleccionada por el método aleatorio estratificado). En consecuencia, una extensión a toda la población de píxeles de la cartografía de usos de suelo con un nivel de significación de 0,1 , permite asegurar con un $90 \%$ de probabilidad que la fiabilidad real del mapa se encuentra en $78,83 \% \pm 3,73$. En este sentido la validación es considerada adecuada ya que autores como Chuvieco Salinero (2008) y Olaya (2014) recomiendan una precisión superior al $80 \%$ y $75 \%$ respectivamente, por otro lado se deben considerar las características de los insumos empleados en cuanto a resolución espacial y la heterogeneidad propia de los centros urbanos en cuanto a respuesta 
2018) generado con la misma metodología utilizada para los mapas de usos del suelo de los año 1990 y 2010, que sirve de comparación con una simulación creada a estos efectos para el año 2018.

\section{SELECCIÓN DE VARIABLES}

Para determinar si las variables explicativas escogidas son buenas o al menos útiles se aplicó el test de correlación V de Cramer (incluido dentro del Land Change Modeler-LCM) que "permite calcular la fuerza de la relación entre variables que pueden presentarse en una tabla de contingencia mayor a 2x2" (Díaz Pacheco y Hewitt, 2013, p. 12) con valores que varían entre 0 y 1 . El valor $V$ viene acompañado de otro valor $p$ que muestra la probabilidad de que $V$ no sea tan diferente de 0 . Un valor alto de $V$ es un buen indicador del poder explicativo de la variable siempre y cuando se lo considere acompañado por un valor de probabilidad $p$ bajo. Un valor bajo de $\mathrm{V}$ indica que la variable puede descartarse.

\section{CÁlCULO DE POTENCIALES DE TRANSICIÓN}

Para generar un mapa de potencial de transición, que indica la probabilidad de que un determinado uso de suelo mute a otro, se usaron Redes Neuronales Artificiales (RNA). Una RNA consiste en una red conectada de unidades de procesamiento (nodos) que son modeladas según las propiedades más elementales de las neuronas del cerebro humano e intenta reproducir su funcionamiento aprendiendo a partir de los datos que se le suministran y de la experiencia que adquieren en su fase de entrenamiento. Los nodos hacen las veces de las neuronas humanas que se encuentran interconectados formando capas ordenadas según su importancia y se activan transmitiendo la información según una 'función binaria de activación', generando un proceso encadenado. Las conexiones entre nodos pueden darse con pesos o importancias diferentes. En general, las RNAs persiguen recrear cómo procesaría el cerebro humano los problemas de datos espaciales, convirtiendo los datos de entrada (capas) en un resultado deseado. Es importante aclarar que toda la operación de una red neuronal funciona como una caja negra (Eastman, 2012).

A partir del conocimiento de la situación de los usos del suelo en dos momentos (1990 y 2010), se intenta reproducir los cambios en los mismos para poder simularlos en momentos futuros. El reconocimiento de los patrones de cambios depende de un proceso de entrenamiento de la red, en el cual interviene el ajuste de los pesos de entrada en cada neurona hasta que la salida se aproxime a una deseada. La fase de aprendizaje de la red finaliza cuando los valores de los pesos dejan de cambiar. La red 'recuerda' lo aprendido en este proceso de entrenamiento $y$, con los datos de entrada provistos a la red, se pasa al uso de la red.

El LCM utiliza una RNA de perceptrón multicapa (MLP), una de las RNAs más ampliamente utilizadas (Pijanowsky, Brown, Shellito y Manik, 2002). MLP contiene una capa de entrada, una capa intermedia (oculta) y otra de salida, las cuales contienen nodos ocultos responsables del funcionamiento del sistema pues actúan tanto en la etapa de aprendizaje como de uso. Cuando se activa el modelo, el proyecto LCM extrae aleatoriamente muestras (de las áreas que han cambiado y de aquellas áreas que fueron elegidas para cambiar pero no lo hicieron) de los dos mapas de usos de suelo utilizados en el análisis de cambios de usos del suelo, la mitad es utilizada para entrenar el modelo y la otra mitad para validarlo.

espectral (Da Silva, Insaurralde y Cardozo, 2014). 
MLP de LCM cuenta con la opción de ser usado con una configuración automática (configuración utilizada en este trabajo) mediante la cual si el testeo se reinicia automáticamente, los pesos se reasignan nuevamente de forma aleatoria a la nueva muestra y la tasa de aprendizaje (learning rate) se reduce a la mitad.

(...) El propio programa toma sus decisiones acerca de los parámetros a utilizar y cómo deberían ser cambiados para modelar mejor los datos; éste, mediante un procedimiento de aprendizaje dinámico, monitorea y modifica el índice de aprendizaje inicial y final; si se detectan oscilaciones significativas en el error RMS los índices de aprendizaje se reducirán a la mitad y

el proceso comenzara nuevamente. (Gallardo Beltrán, 2014, p. 420)

Los demás parámetros de MLP son tomados por LCM en sus valores por defecto. Sin embargo, LCM sí aplica modificaciones espaciales a la información de salida cuando oculta de los potenciales de transición todos los casos de cualquier transición específica que no coinciden con el caso from (desde) (Eastman, 2012).

Al iniciar el proceso, el modelo asigna valores de pesos aleatorios a la capa de entrada y los compara con la capa de salida esperada. Luego de ser incorporadas todas la variables a la red neuronal se determina el error medio cuadrático (RSM) observado y el esperado para todas las observaciones y se ajustan las matrices de ponderación, distribuyendo el error en toda la red de forma uniforme. Este proceso conforma un ciclo, el cual se repite hasta que los valores de salida producen cada vez menos diferencias (teniendo en cuenta el nivel de error calculado). En general se trata de entre $4.000 \mathrm{a}$ 10.000 ciclos. Una tasa de precisión que ronde el $80 \%$ es aceptable (Eastman, 2006, en Mishra, Rai, y Mohan, 2014).

Los valores de ponderación obtenidos se almacenan para ser usados posteriormente sobre las capas de entrada relacionándolas con las variables analizadas, para obtener mapas de potenciales de transición.

En síntesis, combinando los mapas de usos de suelo de ambos años con los factores explicativos (datos de entrada), se obtienen, mediante una RNA de perceptrón multicapa, mapas de 'potenciales de transición' que muestran la probabilidad de que un uso de suelo (o un conjunto de usos dependiente de una misma fuerza dominante) se transforme en otro (estos pares de posibles cambios de usos e.g INF a AUC se denominan 'submodelos'). Para este estudio, los submodelos escogidos fueron de INF a AUC, de CCA a AUC, de AVCVU a AUC y de AP a AUC.

\section{SIMULACIÓN DE ESCENARIOS FUTUROS}

La fase siguiente corresponde a la simulación prospectiva en la que se utilizan índices de cambios y el mapa de potencial de transición ya generado, que determina la influencia de las variables empleadas en los cambios futuros, es decir a los cambios sucedidos entre el tiempo inicial y final, para luego calcular una cantidad relativa de transición a una fecha futura (en este caso 2018 y 2030). Este análisis se basa en el uso de cadenas de Markov.

La predicción de cambio de usos del suelo puede ser 'dura' (hard prediction) en la que la asignación del uso de suelo para cada celda se vale del modelo de asignación MOLA (Multi-objective Land Allocation) que "resuelve conflictos de asignación cuando dos o más células coinciden en los valores de transición potencial para albergar un estado de uso de suelo concreto" (Díaz Pacheco y Hewitt, 2013, p. 15), es una propuesta del estado de las mismas categorías de usos del suelo de la fase de calibración $\left(t_{0}\right.$ y $\left.t_{1}\right)$, en el tiempo $t_{2}$ (Camacho Olmedo, Molero Melgarejo y Paegelow, 2010). Asimismo, es posible 
obtener un mapa de predicción 'blanda' (soft prediction) ${ }^{10}$ que muestra el grado de las diferentes áreas de precipitar al cambio.

\section{CALIBRACIÓN Y VALIDACIÓN}

Calibrar un modelo implica intervenir en el proceso de producción del mismo con el fin de que aquel sea lo más consistente posible con los datos de base usados (GaIlardo Beltrán, 2014). Este paso fue realizado introduciendo u omitiendo variables explicativas, $y$ haciendo correr el modelo en reiteradas oportunidades y modificando en cada una de ellas las probabilidades de transición de cada uso del suelo (tanto en cantidad como en localización).

Respecto de la validación

se entiende el proceso de validación como una valoración objetiva del grado de ajuste de las reglas establecidas por el modelo basado en RNA, y no una confirmación automática de la aplicabilidad de los resultados del trabajo. Por lo tanto, un modelo validado no es necesariamente un buen modelo. (Díaz Pacheco y Hewitt, 2013, p.15)

Pero si es un modelo sobre el que se ha probado una exactitud satisfactoria, considerando sus condiciones particulares.

La comparación se realiza inicialmente de manera visual y posteriormente se aplican métodos estadísticos al mapa validado para el año 2018 mediante el porcentaje de fiabilidad global y los índices Kappa $(K)^{11}$.

En este trabajo, se ha recurrido para comparar los resultados de las simulaciones al software Map Comparison Kit (MCK) desarrollado en Holanda por el Research Knowledge System Institute (RIKS), que permite obtener diferentes medidas de confiabilidad como así también cartografía relacionada a tales medidas.

En primer lugar se realizó una comparación celda por celda por cada categoría entre el mapa simulado para el año 2018 y el considerado 'verdad de terreno'. Esta comparación brinda al usuario información sobre la ocurrencia de la categoría seleccionada en ambos mapas. El resultado arroja métricas que resumen el porcentaje de acuerdo y desacuerdo. Se define como 'acuerdo' a la coincidencia en la asignación de usos del suelo en cada pixel en los momentos de análisis.

El cálculo de $K$ se basa en la comparación directa de un mapa celda por celda, que considera para cada par de celdas en los dos mapas si son iguales o no. Su valor se determina de la siguiente manera:

$$
\begin{aligned}
K= & P(A)-P(E) \\
& 1-P(E)
\end{aligned}
$$

Donde $P(\mathrm{~A})$ representa el acuerdo observado y $P(\mathrm{E})$ representa el acuerdo esperado

10 Los valores de probabilidad obtenidos se han clasificado como 'baja' cuando se encuentren entre 0 y 0,3 ; 'débil' cuando se encuentren entre 0,3 y 0,5; 'moderada' cuando se encuentren entre 0,5 y 0,8 ; y 'alta' cuando se encuentren entre 0,8 y 1 .

11 Otra alternativa es utilizar el Kappa Fuzzy que se basa en la comparación celda a celda de un par de mapas de conjuntos difusos, que tiene en cuenta la vecindad de una celda para expresar la similitud de esa celda en un valor entre 0 (completamente distinto) y 1 (totalmente idéntico). Para distinguir diferencias menores de diferencias importantes, la comparación de mapas de conjuntos difusos tiene en cuenta dos tipos de borrosidad: borrosidad de categoría y borrosidad de ubicación. Sobre la base del mapa de similitud difusa, se calculan dos índices de similitud global: similitud media y Fuzzy Kappa (RIKS, 2010). 
Por su parte, la estadística $K$ resulta de dos tipos de similitud: similitud de cantidad (número total de celdas tomadas por cada categoría) y similitud de ubicación (se refiere a la distribución espacial de las diferentes categorías en el mapa). Para reconocer en qué medida la similitud de ubicación y cantidad están representadas en el estadístico $K$, se divide en dos estadísticas: Kappa Histo $\left(K_{\text {Histo }}\right)$ y Kappa Location $\left(\mathrm{K}_{\mathrm{Loc}}\right)$

$$
K=K_{\text {Histo }} * K_{\text {Loc }}
$$

El valor de $K$ y las estadísticas relacionadas se calculan tanto para el mapa completo como para las categorías individuales que se encuentran en la leyenda.

\section{RESULTADOS}

\section{SELECCIÓN DE VARIABLES}

La selección de variables analizadas depende entre otros aspectos de las características biofísicas propias de cada ciudad (alturas, presencia de cuerpos y cursos de agua, infraestructura frente a posibles inundaciones), de la presencia de sectores centrales (centro de la ciudad tomado desde la plaza principal o el centro administrativo y comercial establecido por ordenanza municipal local vigente) y de la normativa vigente referida a la zonificación y al ordenamiento territorial. Asimismo, dicha selección se basa en la lectura de los antecedentes expuestos previamente y en la bibliografía de uso de esta metodología.

A continuación se exponen las variables exploradas en función del valor de $\mathrm{V}$ de Cramer calculado con el LCM. Tomando en cuenta la bibliografía consultada, se consideraron útiles aquellas variables cuyo valor de $\mathrm{V}$ de Cramer alcanzó el 0,1 (en ciertos casos dicho valor se ha alcanzado redondeando los valores a la primera cifra decimal) y el valor de probabilidad $p$ resultante sea bajo (Tabla 1).

\section{Tabla 1. Variables exploradas a través de la V de Cramer}

Distancia a la zona cívico, Administrativa y Comercial $(\mathrm{V}=0,1$. $)$

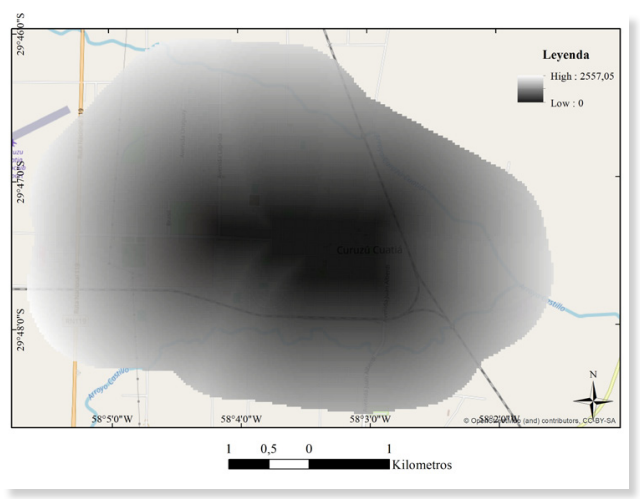

$$
\operatorname{MDE}(V=0,3 .)
$$

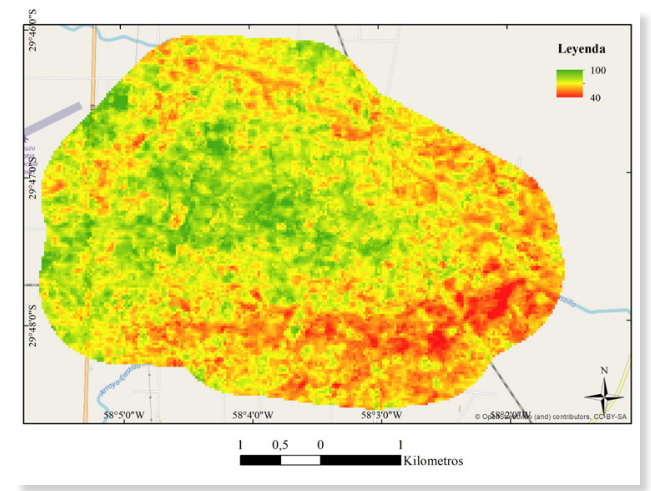


Distancia al AUC de $1990(\mathrm{~V}=0,1$. )

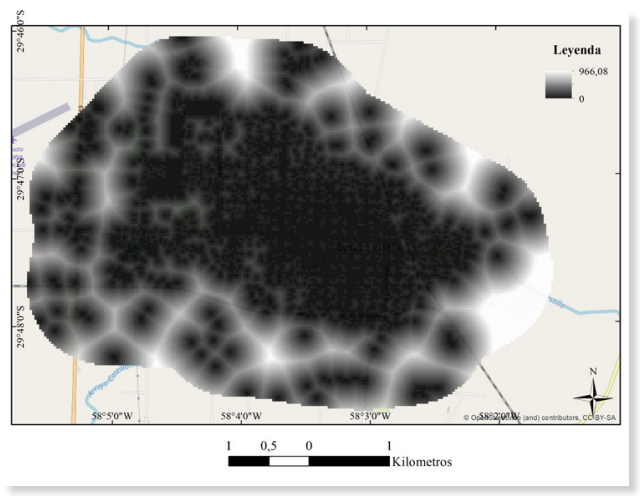

Área Inundable y no inundable $(V=0,3$. $)$

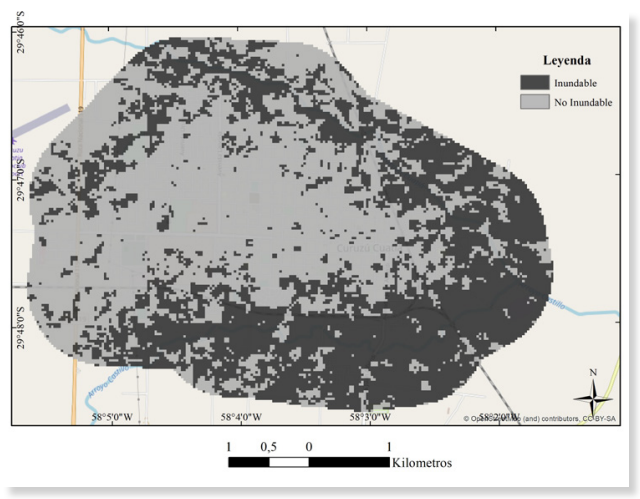

Distancia a equipamientos educativos $(\mathrm{V}=0,1$. $)$

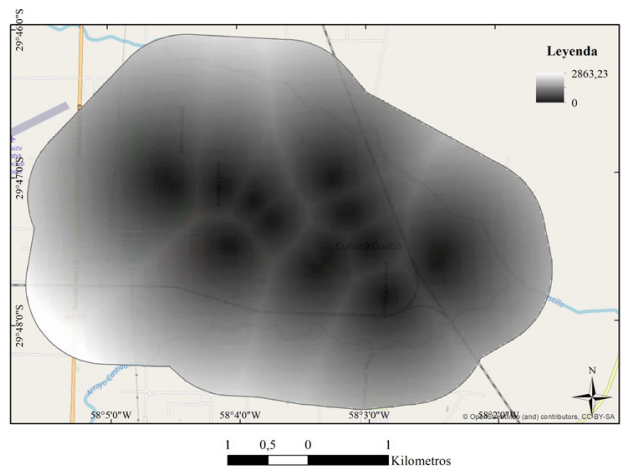

Distancia a los Cursos de Agua $(\mathrm{V}=0,1$. $)$

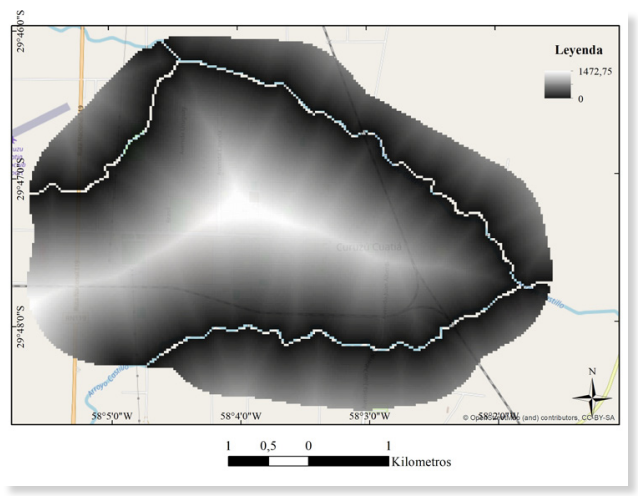

Pendiente $(\mathrm{V}=0,3$. $)$

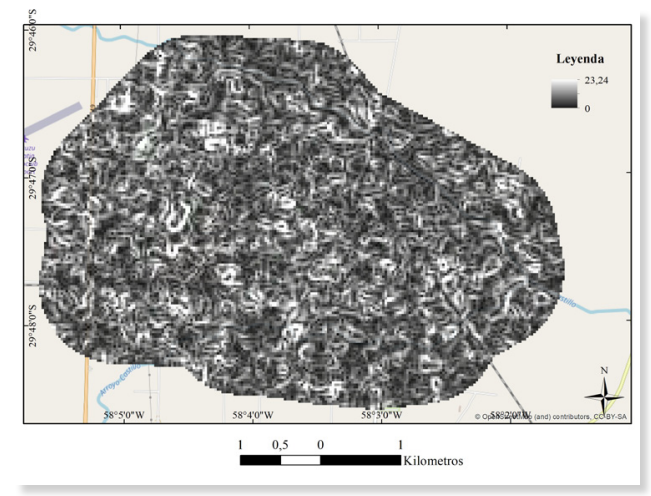

Distancia a Rutas Nacionales y Provinciales $(\mathrm{V}=0,1$.)

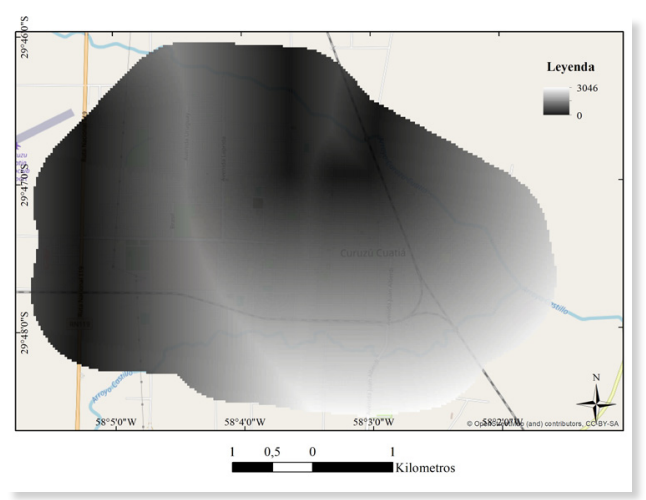


Distancia a Áreas Verdes $(\mathrm{V}=0,1$. $)$

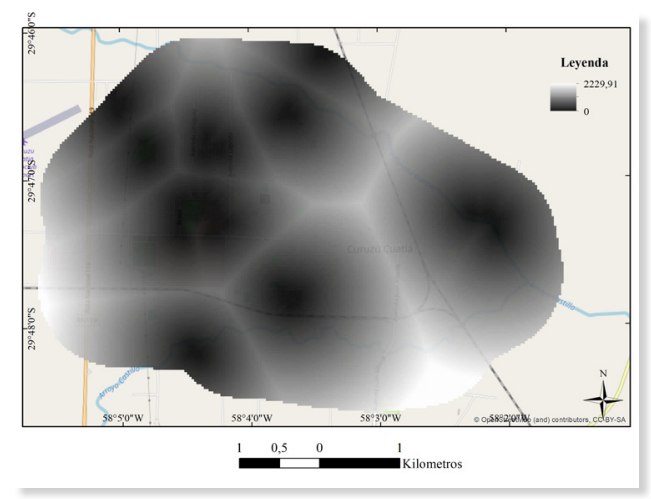

* Se le aplicó una transformación denominada posibilidad de evidencia, la que permite incorporar variables categóricas al análisis. La opción MLP no requiere que las variables estén linealmente relacionadas, pero la transformación a veces puede facilitar la resolución en casos de falta de linealidad fuerte y arrojar así una precisión mayor (Eastman, 2012).

Fuente: elaboración personal

Cálculo de potenciales de transición. Escenario simulado para el año 2030

Como se expuso en párrafos anteriores, los potenciales de transición generados permiten observar qué tan probable es que un tipo de uso de suelo (o grupo de ellos) mute hacia otro, este cambio depende del comportamiento de las variables escogidas y es un input necesario para el paso siguiente que consiste en la creación de escenarios de trayectoria lineal en un futuro.

Para la producción de los potenciales de transición se integraron todas las variables escogidas en el paso anterior y se ejecutó el proceso de RNA que permite alcanzar los mismos. En la Tabla 2 se exponen tales mapas de transición con su correspondiente porcentaje de acierto en función de las variables seleccionadas ${ }^{12}$. Como puede observarse los potenciales de transición solo se modelan para el cambio en el año inicial, es decir si por ejemplo la transición fuera del AP al AUC, los valores de probabilidad generados serán únicamente para los píxeles que hayan sido clasificados como AP en el año 1990.

El escenario simulado al año 2030 (Mapa 4, Hard Prediction) se corresponde con uno de trayectoria lineal, es decir el comportamiento tendencial que supone que la influencia de las variables seleccionadas será la misma que la ocurrida entre los años 1990 y 2010. Concluido el proceso se evidencia la importante dinámica que se experimentará en el área de estudio bajo los supuestos ya expuestos.

12 Si bien este valor, como se hizo referencia en el apartado de metodología, se considera aceptable cuando alcanza el $80 \%$, en este estudio se consideraron porcentajes de acierto menores tal como se lee en algunos antecedentes consultados (Mishra, et al., 2014) en cuyo trabajo se aceptó un valor del 50,8\%. 
Tabla 2. Potenciales de Transición de cada clase a la categoría AUC y su correspondiente porcentaje de acierto

INF a $\operatorname{AUC}(73,02)$

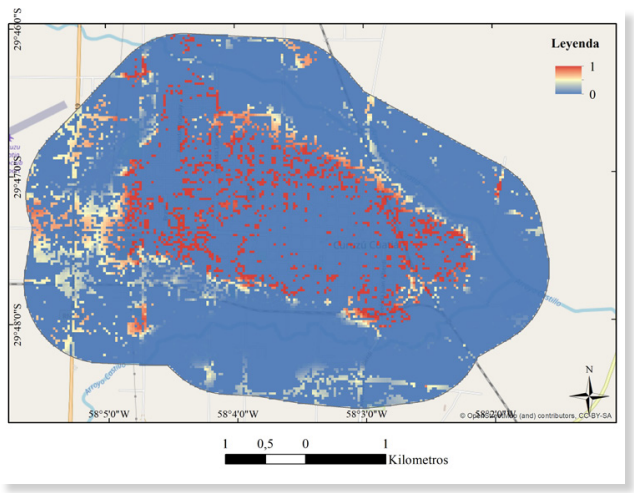

AVCVU a AUC $(72,22)$

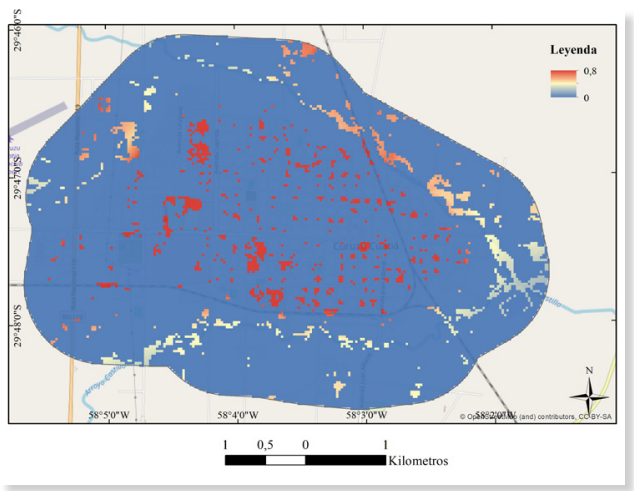

$\operatorname{CCA}$ a $\operatorname{AUC}(74,50)$

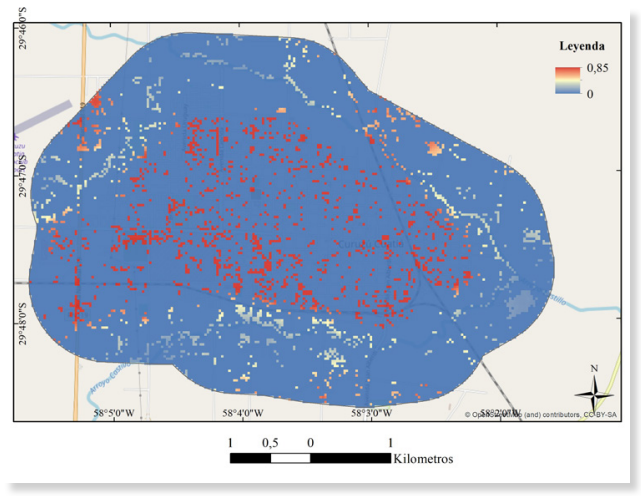

$\operatorname{AP}$ a $\operatorname{AUC}(79,05)$

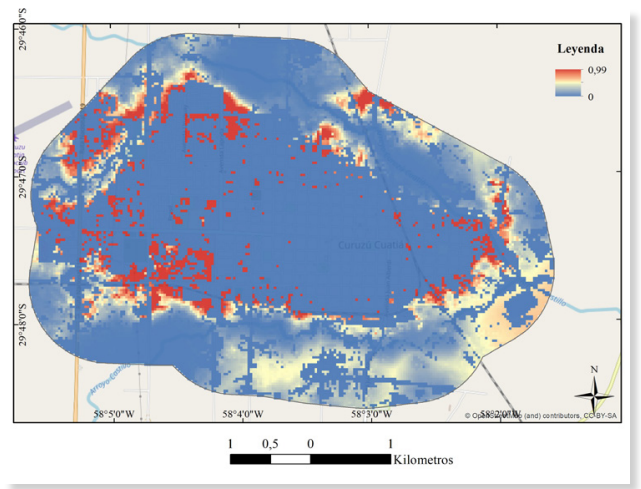

Fuente: elaboración personal

Mapa 4. Escenario de trayectoria lineal. Usos de suelo para el año 2030

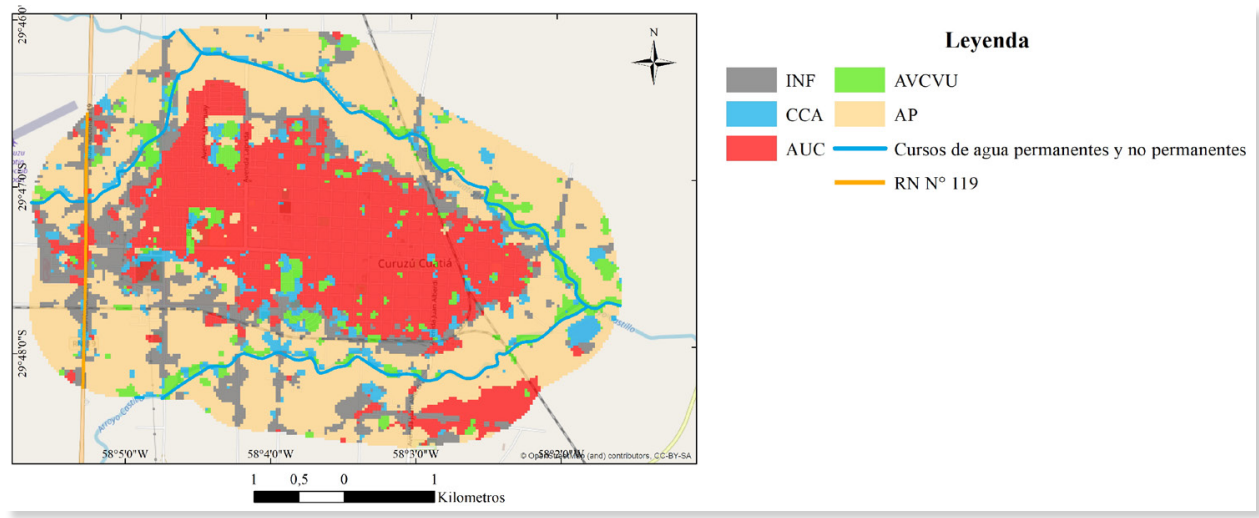

Fuente: elaboración personal

La clase AUC muestra un fuerte sostenimiento y se afianza ya que en el año 2030 disminuyen aquellos espacios internos o intersticios sin ocupar, e incluso desaparecen del escenario futuro. Asimismo, y apoyándonos también en las tendencias generales calculadas mediante el polinomio de tercer grado (up supra) se aprecia un avance de la clase AUC hacia la Ruta Nacional No 119 en las proximidades o el acceso principal de 
la ciudad. También es posible observar un aumento considerable de la clase AUC en el sector sur de la ciudad (Mapa 5), aspecto que llama la atención ya que se trata del sector de menores alturas según el Modelo Digital de Elevación expuesto entre las variables elegidas para hacer correr el modelo, situación que enfrentará una posible urbanización en sectores anegadizos. Esta última evidencia ejemplifica la utilidad de contar con un insumo que colabore en el ejercicio de la planificación territorial de una ciudad. De esta manera, el desarrollo o avance del área urbana podría ser pensado de antemano buscando evitar consecuencias o externalidades negativas para la población y el ambiente.

Mapa 5. Avance de la mancha urbana entre 1990 y 2030

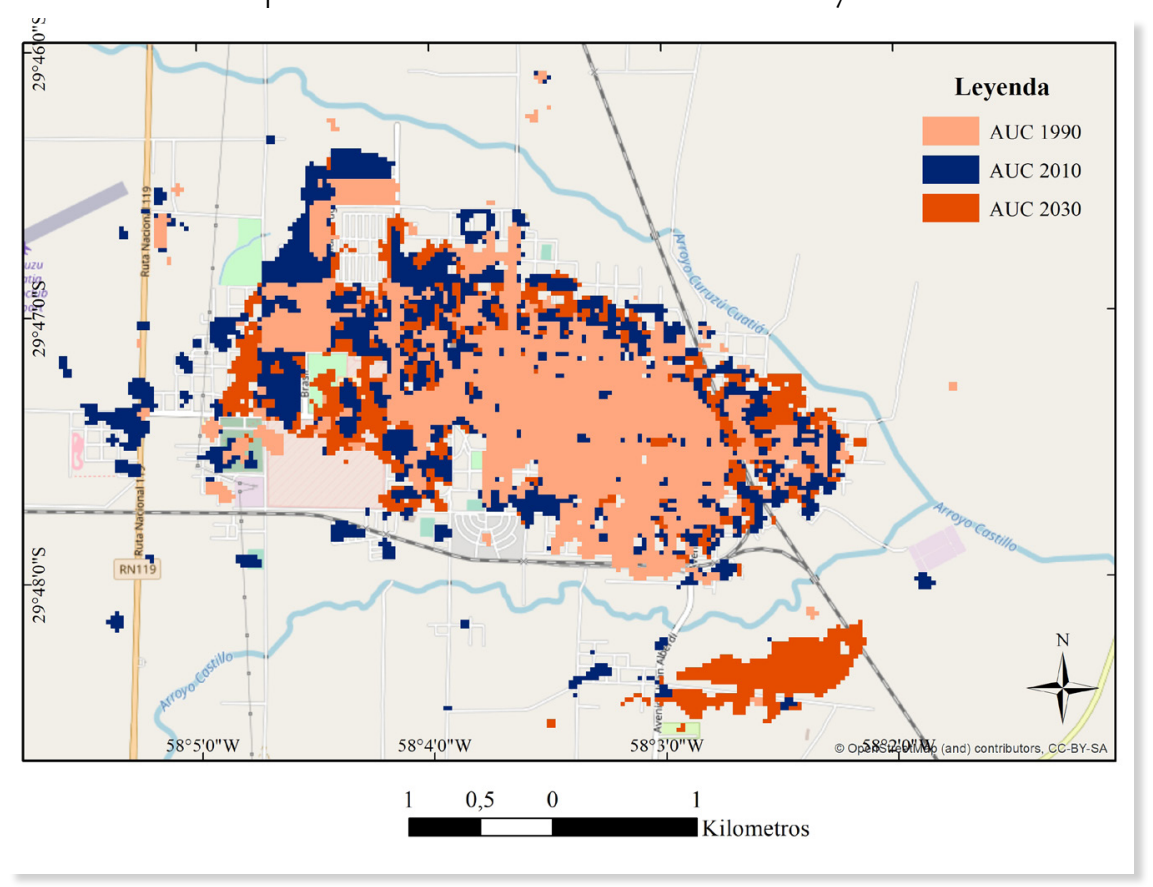

Fuente: elaboración personal

Las áreas de alta probabilidad de cambios (Mapa 6, Soft Prediction) se encuentran en las proximidades de los sectores ya clasificados como AUC (tanto en su interior como en los bordes), con una mayor concentración en el sector oeste suroeste. Con probabilidad moderada, y dibujando una continuidad con los sectores anteriormente nombrados, cambiarían hacia el AUC los espacios localizados en proximidades de la Ruta Nacional $N^{\circ} 119$ (oeste suroeste) y en el sector sureste de la ciudad, en cercanías de las vías del ferrocarril y sobrepasando el arroyo otrora límite natural de la ciudad. Asimismo, se observa un valor moderado de probabilidad de cambio hacia el AUC en el sector este de la ciudad (nuevamente sobrepasando los arroyos existentes).

En síntesis, en la Tabla 3 se muestra la evolución de la superficie de cada clase (valores absolutos y porcentuales) en un periodo de 40 años. Como puede observarse, el AUC es la única clase cuya superficie se comporta de forma creciente en los tres momentos de análisis. Este comportamiento ha hecho que en el año 1990 sea la clase cuya proporción de superficie respecto del total la situaba en cuarto lugar (16,2 \%), mientras que para el año 2010 alcanzó el segundo lugar (19,9\%), manteniendo este orden de proporción en el 2030 (26,4\%). En términos absolutos pasará de tener 376,11 ha en 1990 a 612,18 ha en 2030 , lo que se traduce en un aumento del 62,76\% de superficie en el lapso de 40 años. 
Se estimó además que las superficies del AVCVU y el AP aumenten en este periodo un $68 \%$ y $18,3 \%$ respectivamente. Por su parte, para la INF y los CCA se determinaron descensos del $35,05 \%$ y del $53,68 \%$ respectivamente en el mismo periodo (Tabla 3 ).

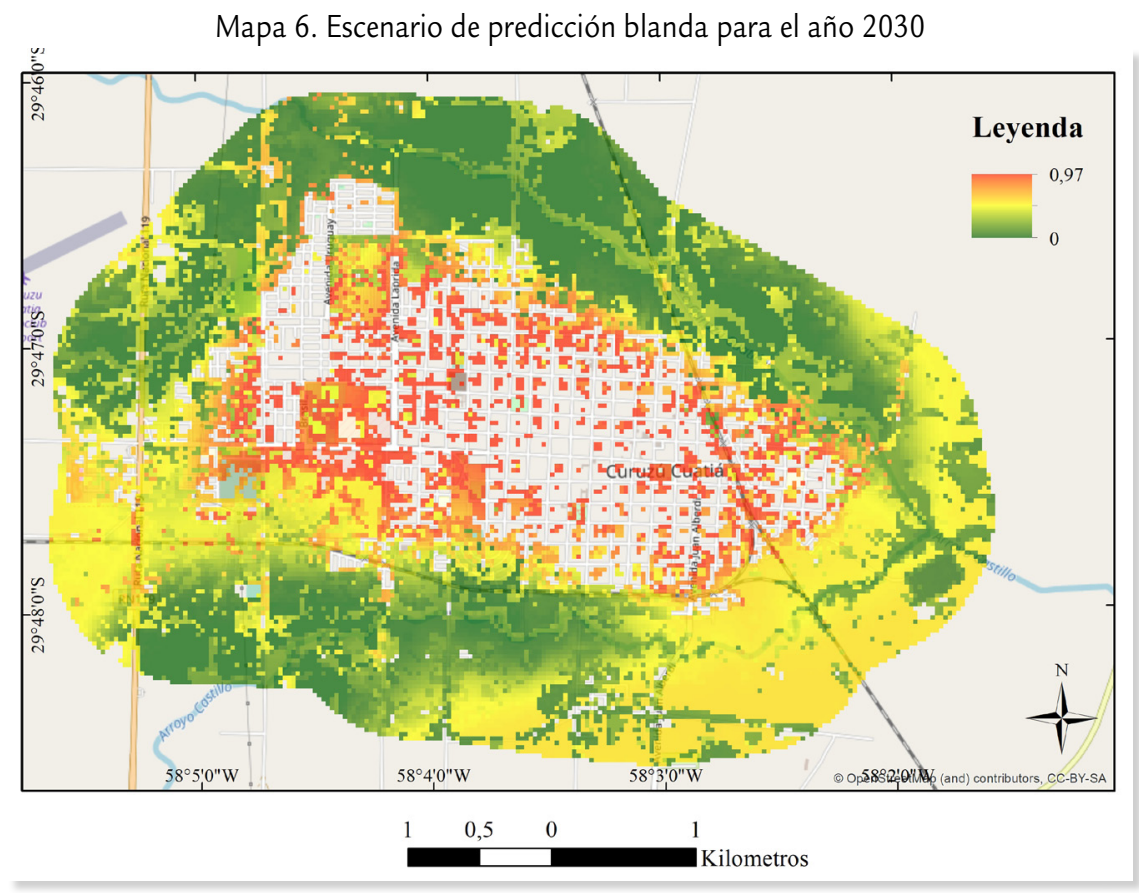

Fuente: elaboración personal

Tabla 3. Superficie de cada clase en 1990, 2010 y 2030. Valores expresados en hectáreas y en porcentajes

\begin{tabular}{|c|c|c|c|c|c|c|c|c|}
\hline CLASE & $\begin{array}{c}\text { Superficie año } \\
1990 \text { (ha) }\end{array}$ & $\%$ & $\begin{array}{c}\text { Superficie año } \\
2010 \text { (ha) }\end{array}$ & $\%$ & & $\begin{array}{c}\text { Superficie año } \\
2030 \text { (ha) }\end{array}$ & $\%$ & \\
\hline INF & 538,83 & 23,27 & 450,81 & 19,5 & 8 & 350,01 & 15,1 & $\sqrt{2}$ \\
\hline CCA & 493,38 & 21,31 & 229,14 & 9,9 & $\sqrt{3}$ & 228,51 & 9,9 & $=$ \\
\hline AUC & 376,11 & 16,2 & 460,35 & 19,9 & 仓 & 612,18 & 26,4 & 仓 \\
\hline AVCVU & 103,77 & 4,48 & 181,53 & 7,8 & 仓 & 174,33 & 7,5 & ת \\
\hline AP & 803,43 & 34,7 & 993,69 & 42,9 & 仓 & 950,49 & 41,1 & $\Omega$ \\
\hline
\end{tabular}

Fuente: elaboración personal

\section{VALIDACIÓN}

\section{COMPARACIÓN POR CATEGORÍA}

Mediante el uso del MCK (up supra) fue posible comparar celda a celda cada clase y generar un mapa que permita visualizar la distribución espacial de los acuerdos y desacuerdos (Mapa 6) cuyos resultados se incluyen en la Tabla 4.

El modelo considerado (con las variables escogidas) simula 104,58 ha (1.662 píxeles) en el AUC que no corresponden a tal clase y a la vez, existen 149,85 ha (1.665 píxeles) que corresponden a la misma y no fueron simulados (en el espacio correspondiente). En el Mapa 7 se puede observar la localización de los píxeles según hayan experimentado un acuerdo o no, entre el mapa simulado para el año 2018 y el considerado 'verdad de 
terreno'. Claramente, la mayor proporción de píxeles clasificados como AUC y coincidentes en ambos mapas se presenta al interior de la clase. Los píxeles simulados incorrectamente según su localización se encuentran también distribuidos en toda el área y se visualizan pocos espacios pero de mayor superficie al sur sureste. Los píxeles que debieron ser simulados en la clase AUC y no lo fueron se distribuyen en los alrededores la misma con espacios de mayor superficie en el sector sur suroeste.

Tabla 4. Acuerdos y desacuerdos experimentados por la clase AUC para el año 2018. Valores en hectáreas ${ }^{*}$ y porcentajes

\begin{tabular}{lccc}
\hline & Acuerdo & Solo simulado & $\begin{array}{c}\text { Solo en "verdad } \\
\text { de terreno" }\end{array}$ \\
\hline $\begin{array}{l}\text { Clasificado como AUC } \\
696,24 \text { ha }\end{array}$ & 396,81 ha & 104,58 ha $^{* *}$ & 149,85 ha \\
\cline { 2 - 4 } & $56,99 \%$ & $21,48 \%$ & $21,58 \%$ \\
\hline
\end{tabular}

* El Software MCK arroja valores que representan cantidad de píxeles

${ }^{* *}$ Este valor representa el $4,52 \%$ de la superficie total simulada por el modelo.

Fuente: elaboración personal

Mapa 7. Espacialidad de los acuerdos y desacuerdos experimentados por la clase AUC en el año 2018

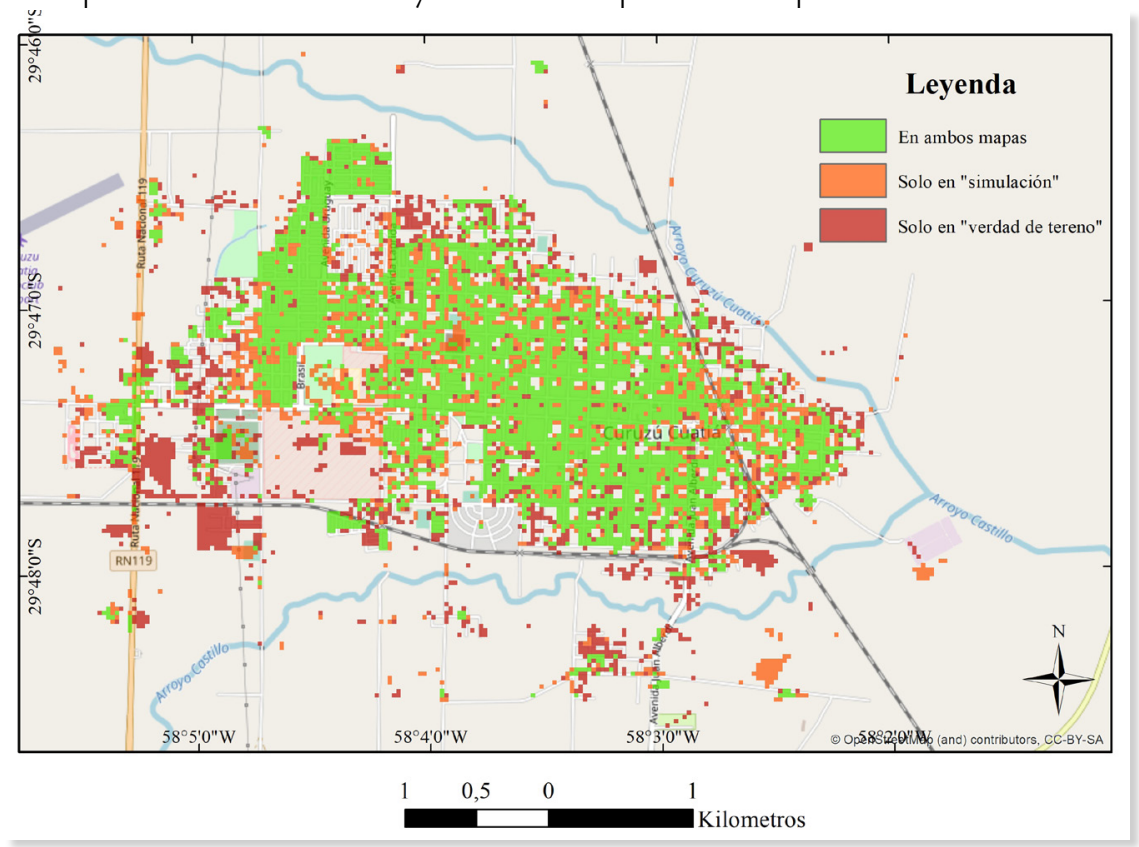

Fuente: elaboración personal

\section{Fiabilidad Global y Método de Comparación Kappa}

En esta etapa de la validación del modelo se determinó por un lado la fiabilidad global del mapa simulado, y por otro el porcentaje de concordancia de píxeles tanto en cantidad $\left(K_{\text {Histo }}\right)$ como en localización $\left(K_{\text {Loc }}\right)$ que se resumen en un único valor $K$ que refleja el grado de acuerdo entre las cartografías comparadas. Esta última terna de valores se obtuvo para el mapa completo y para cada categoría incluida en el mismo.

La fiabilidad global obtenida fue del $51,9 \%$ y los valores de kappa para el mapa completo fueron: $K_{\text {Loc }}=0,493, K_{\text {Histo }}=0,766$ y $K=0,378$, es decir, hubo un alto porcentaje de similitud en cantidad y un porcentaje medio de similitud en localización, 
lo que se resume en un porcentaje de acuerdo justo ${ }^{13}$ según la clasificación realizada por Landis y Koch (1977).

El análisis de estos valores permite identificar en qué proporción las diferentes categorías aportan al valor de $K$ calculado para el mapa completo. En este sentido, existe una mayor fuerza de acuerdo en la clase AUC (sustancial) seguidas por el AP (moderado), el AVCVU, la INF (justa) y en menor medida los CCA (ligera).

Respecto de la localización, el AP y el AUC son las que experimentaron mejores acuerdos, seguidas por las clases AVCVU e INF, y en menor medida por los CCA.

En relación a la similitud en cantidad, los valores expuestos muestran coincidencias altas entre asignaciones en el mapa considerado 'verdad de terreno' y el simulado. En particular, el AUC experimenta una coincidencia total de asignación, lo cual se considera lógico dado que el estudio hace hincapié sobre el comportamiento de esta categoría.

Las ternas de valores Kappa para cada categoría se detallan en la Tabla 5.

Tabla 5. Valores $K_{\text {Loc }}, K_{\text {Histo }}$ y $K$ para cada clase

\begin{tabular}{cccccc}
\hline & INF & CCA & AUC & AVCVU & AP \\
\hline$K_{\text {Loc }}$ & 0.311 & 0.131 & 0.642 & 0.376 & 0.728 \\
\hline$K_{\text {Histo }}$ & 0.837 & 0.606 & 1 & 0.821 & 0.607 \\
\hline$K$ & 0.26 & 0.079 & 0.641 & 0.308 & 0.442 \\
\hline
\end{tabular}

Fuente: elaboración personal

\section{DISCUSIÓN DE LOS RESULTADOS}

En función de las fuentes empleadas y la metodología abordada fue posible obtener los resultados expuestos en el apartado anterior que muestran la concreción del objetivo del presente trabajo: generar un escenario de usos de suelo de trayectoria lineal para el año 2030 en la ciudad de Curuzú Cuatiá, provincia de Corrientes, Argentina. En este sentido, fue necesaria la determinación del conjunto de variables consideradas 'importantes' para la expansión de la ciudad y, como consecuencia, los cambios en el uso del suelo. En términos generales, es posible afirmar que los cambios y el incremento de AUC son influenciados por todas las variables seleccionadas a excepción de la pendiente.

Otros resultados muestran un claro aumento de la superficie del AUC entre los momentos analizados y la espacialización de aquellos sectores donde existe mayor probabilidad de que ocurran transiciones de cada una de las clases definidas hacia el AUC. Estos resultados se configuran como antecedentes de lo que podría llegar a suceder en un momento futuro. Al respecto, en todos los casos se observan probabilidades altas de que las clases aporten a la consolidación de la ciudad cubriendo espacios al interior de lo clasificado como AUC en el año 1990, y probabilidades altas y medias de ocurrencia de cambios hacia el AUC en proximidades al acceso principal de la ciudad. También se aprecia la presencia de probabilidades medias y medias-altas de que sectores de meno-

13 Landis y Koch (1977), establecieron la siguiente clasificación en la fuerza de acuerdo al comparar dos mapas con datos categóricos, en base a los valores de kappa obtenidos: $K<0$, fuerza de acuerdo "pobre"; $0 \leq K \leq 0,2$, fuerza de acuerdo 'ligera'; $0,21 \leq K \leq 0,4$, fuerza de acuerdo 'justa'; $0,41 \leq K \leq 0,6$, fuerza de acuerdo 'moderada'; $0,61 \leq K \leq 0,8$, fuerza de acuerdo 'sustancial'; y $0,81 \leq K \leq 1$, fuerza de acuerdo 'casi perfecta'. 
res elevaciones (según la combinación de la información brindada por los potenciales de transición y el MDE utilizado) muten hacia el AUC, lo que implicaría el avance de la ciudad sobre sectores anegadizos potencialmente inundables.

Para confirmar lo expuesto en el párrafo anterior, el escenario de predicción dura simulado al año 2030 muestra el avance de la ciudad en los sectores antes mencionados y su análisis, en conjunto con el escenario de predicción blanda, permitiría contar con un insumo más para los planificadores del territorio al considerarse un elemento extra para el aumento de la certeza sobre lo que podría llegar a suceder en relación a cierto proceso (en estados pasados y en un momento futuro).

En síntesis, la información recabada puede ser utilizada con intención de corregir o al menos minimizar los errores ocurridos en el pasado y sus consecuentes efectos en cuanto al ordenamiento y planificación del territorio, con miras a la preservación de los espacios ambientalmente críticos y a un desarrollo más sustentable.

Por último, respecto del proceso de validación, a nuestro juicio y en función de la bibliografía consultada, la utilización de un mapa validado para el año 2018 y su comparación con una simulación al mismo año mediante el modelo calibrado con parámetros y mapas pasados (año 1990 y 2010), se considera una forma recurrente y aceptada para evaluar el grado de validez del modelo mencionado. Sin embargo, se debe mencionar que esta evaluación se realiza sobre el supuesto de que los datos iniciales son totalmente correctos, lo cual introduce un error inevitable, sumado al hecho de que el valor de kappa se calcula en base a la comparación directa pixel a pixel y resume el acuerdo en localización y en cantidad de píxeles. Teniendo en cuenta la complejidad y la dinámica del objeto de estudio, los materiales utilizados, las variables seleccionadas, los modelos escogidos y todas las limitantes derivadas del tipo de estudio que se desarrollan, entre otros elementos que no han sido considerados (por ejemplo la inclusión de factores sociales), la existencia de errores, entre otros, sería interesante complementar la determinación del grado de validez del modelo con el cálculo del indicador no tan rígido como el fuzzy kappa, que además de contemplar lo que sucede en un punto en particular, considere la influencia del vecindario del mismo y el grado de pertenencia de un punto a una categoría.

\section{CONSIDERACIONES FINALES}

Los cambios en el uso del suelo son una de las consecuencias ineludibles del proceso de expansión urbana, por esta razón es que se considera que este tipo de contribuciones, aportan información territorial de tipo local que colaboran a la construcción del conocimiento de la dinámica del territorio, para que los diferentes actores involucrados puedan realizar una mejor y más eficaz planificación del mismo.

Los resultados del estudio muestran por un lado, la distribución espacial de los usos del suelo definidos, mediante un escenario futuro de predicción dura, generado a partir de estudio enfocado en el avance de la clase AUC. En otras palabras, los cambios que podrían sufrir las clases restantes, considerando el avance del AUC sobre ellas, y determinadas variables seleccionadas previamente. Por otro lado, se obtuvo un mapa de probabilidad de cambios (predicción blanda) que expone el potencial que tienen determinadas áreas para convertirse en un futuro en AUC.

Respecto de la validación de estos resultados, se considera que el modelo es útil para mostrar una posible situación futura de la clase AUC (en función de lo sucedido en el pasado), ya que, aunque la coincidencia celda a celda no presenta valores altos, comparando 
lo sucedido en el año 2018 con lo simulado, efectivamente los cambios del usos del suelo hacia el AUC se produjeron en los sectores que se simulaban con mayor probabilidad.

Por último, cabe mencionar que el avance de la investigación debería realizarse en torno a la búsqueda y exploración de nuevas variables que puedan influir en los cambios de usos del suelo a escala local, que permitan mejorar la aproximación a las situaciones reales, y a la introducción de más indicadores de confiablidad como el valor de fuzzy kappa que se basa en la teoría de los conjuntos difusos.

\section{REFERENCIAS}

Aguilera Benavente, F.; Plata Rocha, W.; Bosque Sendra, J. y Gomez Delgado, M. (2009). Diseño y Simulación de Escenarios de Demanda de Suelo Urbano en Ámbitos metropolitanos. Revista Internacional de Sostenibilidad, Tecnología y Humanismo, (4), 57-80.

Alcamo, J.; Kok, K.; Busch, G. y Priess, J. (2008). Searching for the Future of Land: Scenarios from the Local to Global Scale (pp. 67-103). En J. Alcamo (Ed.) Environmental Futures: The Practice of Environmental Scenario Analysis. Amsterdam: Elsevier.

Baluja Arestiño, J.; Plata Rocha, W.; Gómez Delgado, M. y Bosque Sendra, J. (2010). Análisis de factores explicativos del crecimiento urbano en el Área Metropolitana de Granada mediante técnicas estadísticas y SIG (pp. 640-657). En J. Ojeda, M. Pita e I. Vallejo (Eds.) Tecnologías de la Información Geográfica: La Información Geográfica al servicio de los ciudadanos. Sevilla. Secretariado de Publicaciones de la Universidad de Sevilla.

Buzai, G. y Baxendale, C. (2011). Análisis Socioespacial con Sistemas de Información Geográfica. Perspectiva científica. Temáticas de bases ráster (Tomo 1). Buenos Aires: Lugar Editorial.

Camacho Olmedo, M.; Molero Melgarejo, E. y Paegelow, M. (2010). Modelos geomáticos aplicados a la simulación de cambios de usos del suelo. Evaluación del potencial de cambio (pp. 658-678). En J. Ojeda, M. Pita e I. Vallejo (Eds.) Tecnologías de la Información Geográfica: La Información Geográfica al servicio de los ciudadanos. Sevilla: Secretariado de Publicaciones de la Universidad de Sevilla.

Chuvieco Salinero, E. (2008). Teledetección Ambiental. La observación de la Tierra desde el Espacio. Barcelona: Ariel Ciencia.

Cifuentes Ruiz, P. (2009). Modelización de los factores de crecimiento urbano como aporte a la sostenibilidad. Estudio de caso: Manizales-Colombia. Revista Internacional de Sostenibilidad, Tecnología y Humanismo, (4), 81-96.

Da Silva, C.; Insaurralde, A. y Cardozo, O. (2014). Cartografía de Coberturas del Suelo mediante Sensores Remotos, de la Ciudad de Resistencia, Argentina (2013). Revista Geográfica Digital, IGUNNE, año 11(21). Recuperado de http://hum.unne.edu.ar/revistas/geoweb/default.htm.

Diaz Pacheco, J. y Hewitt, R. (2013). Modelado del Cambio de Usos de Suelo Urbano a través de Redes Neuronales Artificiales. Comparación con dos aplicaciones de software. Revista Internacional de Ciencia y Tecnología de la Información Geográfica, Geofocus, 14, 1-22.

Eastman, J.R. (2012). IDRISI Selva. Guía para SIG y procesamiento de imágenes. Clark University.

Gallardo Beltrán, M. (2014). Cambios de usos del suelo y simulación de escenarios en la comunidad de Madrid. Análisis de tres décadas de transformación territorial y proyección futura. Tesis Doctoral del Departamento de Geografía Humana de la Facultad de Geografía e Historia de la Universidad Complutense de Madrid. 
Gómez, L. y Ramírez, M. (2019). Expansión urbana y cambios en el uso del suelo en la ciudad de Curuzú Cuatiá, Corrientes, Argentina, entre los años 1990 y 2016. Revista de Estudios Marítimos y Sociales, (4). Recuperado de https://estudiosmaritimossociales.org/ archivo/rems-14/dossier-gomez/ (consulta 28 de mayo de 2019).

Instituto Nacional de Estadística y Censos INDEC (2010). Censo Nacional de Población, Hogares y Viviendas. Recuperado de https://www.indec.gob.ar/nivel4_default.asp?id_tema_1=2\&id_tema_2=41\&id_tema_3=135 (consulta 15 de julio de 2017).

La Macchia, L (2014). Modelización del Drenaje Urbano de la Ciudad de Tandil mediante Tecnologías de la Información Geográfica. Geografía y Sistemas de Información Geográfica, GEOSIG, 6, 66-81.

Landis, J. y Koch, G. (1977). The measurement of observer agreement for categorical data. Biometrics, 33(1), 159-174. Recuperado de https://www.jstor.org/stable/2529310

Mishra, V.; Rai, P. y Mohan, K. (2014). Prediction of Land Use Changes based on Land Change Modeler (LCM) Using Remote Sensing: A Case Study Of Muzaffarpur (Bihar), India. Journal of the Geographical Institute 'Jovan Cvijic', 64, 111-127.

Olaya, V. (2014). Sistemas de Información Geográfica. Recuperado de http://www. icog.es/ TyT/files/Libro_SIG.pdf.

Pijanowsky, B.; Brown, D.; Shellito, B. y Manik, G. (2002). Using neural networks and GIS to forecast land use changes: a Land Transformation Model. Computers, Environment and Urban Systems, 26, 553-575.

Plata Rocha, W.; Bosque Sendra, J. y Gomez Delgado, M. (2011). Análisis de Factores Explicativos del Crecimiento Urbano en la Comunidad de Madrid a través de Métodos Estadísticos y SIG. Geografía y Sistemas de Información Geográfica, GEOSIG, (3), 201-230.

Research Institute For Knowledge Systems (RIKS) (2010). Map Comparison Kit 3. User Manual. Maastricht, The Netherlands.

Santos Preciado, J.; Azcárate Luxán, M.; Cocero Matesanz, D.; García Lázaro, F. y Muguruza Cañas, C. (2012). Análisis detallado del crecimiento urbano mediante tecnologías de la información Geográfica (pp. 81-121). En M. Gómez Delgado y V. Rodriguez Espinoza (Coords.) Análisis de la Dinámica Urbana y Simulación de Escenarios de Desarrollo Futuro con Tecnologías de la Información Geográfica. Madrid: RaMa Editorial.

Veldkamp, A. y Lambin, E.F (2001). Editorial: Predicting land-use change. Agricultural, Ecosystems and Environment, 85(1-3),1-6.

Wegener, M. (2000). New Spatial Planning Models. International Journal of Applied Earth Observation and Geoinformation, 3(3), 1-26. Recuperado de http://www.spiekermann-wegener.com/pub/pdf/MW_Enschede_061200.pdf

\section{OTRAS FUENTES}

Ley Provincial N 4.752/1993. Ley Orgánica de las Municipalidades. Artículo N 7, 30 de diciembre de 1993.

Ley Provincial N 5960/ 2010. Propuesta de Regionalización de la Provincia de Corrientes. Artículo $N^{\circ} 39,14$ de mayo de 2010.

Ordenanza Municipal N³59/1986. Artículos N 1 y N² 2, 3 de diciembre de 1986.

Ordenanza Municipal No 2.410/2006 (Anexo). Normas de zonificación y ordenamiento. Título 2.2.1, 14 de diciembre de 2006. 
Laura Fabiana Gómez es Profesora en Matemática. Agrimensora. Especialista en Tecnología de la Información Geográfica. Becaria Doctoral del Consejo Nacional de Investigaciones Científicas y Técnicas (CONICET) con lugar de trabajo en el Departamento de Agrimensura de la FaCENA, UNNE. Doctoranda en la carrera Doctorado en Agrimensura de la Facutad de Tecnología y Ciencias Aplicadas de la Universidad Nacional de Catamarca (UNCa). Jefe de Trabajos Prácticos (por concurso) en la cátedra Teoría de Errores y Compensación (Departamento de Agrimensura) y Auxiliar Docente de Primera (por concurso) en la cátedra Trigonometría (Departamento de Matemática), ambas de la carrera Ingeniería en Agrimensura de la FaCENA, UNNE. Las investigaciones realizadas y en curso se centran en la expansión urbana, cambios de usos de suelo y simulación de escenarios futuros en ciudades intermedias de la provincia de Corrientes. Departamento de Agrimensura. Facultad de Ciencias Exactas, Naturales y Agrimensura (FaCENA). Universidad Nacional del Nordeste. Consejo Nacional de Investigaciones Científicas y Técnicas (UNNE/CONICET). 9 de Julio 1449, (3400) Corrientes, Argentina, laura.f.gomez@gmail.com, ORCID https://orcid.org/0000-0003-2114-3302 